\title{
IL-1 has no direct role in the IGF-1 non- responsive state during experimentally induced arthritis in mouse knee joints
}

\author{
Pernette J Verschure, Leo A B Joosten, Fons A J Van de Loo, Wim B Van den Berg
}

\begin{abstract}
Objective-To investigate the involvement of interleukin-1 (IL-1) in the induction or maintenance of the insulin-like growth factor 1 (IGF-1) non-responsive state of chondrocytes during experimental arthritis in mouse knee joints.

Methods-To characterise IGF-1 nonresponsiveness during arthritis, we measured chondrocyte proteoglycan (PG) synthesis by assaying incorporation of ${ }^{35} \mathrm{~S}$-sulphate into mouse patellar cartilage, obtained from knee joints with experimentally induced arthritis and normal knee joints, cultured with IGF-1. We investigated whether suppressive mediators produced by the arthritic synovium or chondrocytes abolished the IGF-1 stimulation of normal cartilage, and used IL-1 primed cartilage to mimic the arthritic in vivo state. Specific inflammatory mediators responsible for the maintenance of the suppressed IGF-1 response were sought. We measured IGF-1 responsiveness in normal and arthritic patellae cultured with antibodies against tumour necrosis factor (TNF) or IL-1 $\alpha / \beta$, with IL-1 receptor antagonist (IL-1ra), and with several inhibitors of proteolytic enzymes or reactive oxygen species, and analysed the role of $I L-1$ in the development of IGF-1 non-responsiveness by studying IGF-1 responses in cartilage treated with IL-1 antibodies in vivo, at the onset of arthritis.
\end{abstract}

Results-Mediators from the surrounding tissue of both normal and arthritic cartilage suppressed chondrocyte IGF-1 responses. Priming the cartilage with IL-1 did not directly induce IGF-1 nonresponsiveness, but enhanced the ability of suppressive mediators from synovium or chondrocytes to downregulate the IGF-1 responsive state. IL-1ra, IL-1 $\alpha / \beta$ antibody, TNF antibody, or the inhibitors tested did not markedly improve the disturbed IGF-1 response, but treatment with anti-IL-1 at the onset of arthritis prevented the development of IGF-1 non-responsiveness.

Conclusion-IL-1 alone does not induce IGF-1 non-responsiveness and is not critical in the maintenance of this phenomenon. However, IL-1 does appear to be an important cofactor in the generation of the IGF-1 non-responsive state.

(Ann Rheum Dis 1995; 54: 976-982)
Chondrocytes regulate the equilibrium between synthesis and degradation of cartilage matrix molecules in articular cartilage. ${ }^{1}$ Insulin-like growth factor 1 (IGF-1) is the most important anabolic growth factor for chondrocyte metabolism, ${ }^{2-7}$ whereas interleukin-1 (IL-1) is essential for chondrocyte catabolism. ${ }^{8-12}$

In joint diseases such as rheumatoid arthritis (RA), protracted inflammation leads to severe destruction of the articular cartilage and injury of surrounding tissue. Degradation of the matrix proteoglycans (PGs) and inhibition of PG synthesis are the main features of experimentally induced arthritis. ${ }^{13}$ There is compelling evidence that IL-1 and tumour necrosis factor (TNF) act as key mediators in the pathogenesis of inflammatory joint diseases. ${ }^{14-21}$ Moreover, IL-1 has been shown to be a key mediator in cartilage destruction, having a major effect on chondrocyte PG synthesis. ${ }^{22-26}$

A lack of anabolic signalling might contribute to decreased chondrocyte PG synthesis during experimentally induced arthritis. ${ }^{27} 28$ We previously reported that, in contrast to the ability of IGF-1 to sustain chondrocyte PG synthesis in normal mouse articular cartilage during culture, chondrocytes from experimentally induced arthritic knee joints did not respond to IGF-1. ${ }^{27-30}$ This IGF-1 non-responsiveness during arthritis was not caused by general impairment of chondrocyte metabolism. ${ }^{27}$

IL-1 and IGF-1 show counteracting activities: for example, IGF-1 has been reported to increase the recovery rate from IL-1 induced inhibition of chondrocyte PG synthesis, ${ }^{31}$ to promote cartilage pathology by inhibiting IGF-1 mediated anabolism, ${ }^{32}$ to downregulate IGF-1 mRNA levels, ${ }^{33}$ and to induce secretion of IGF binding proteins and increase IGF-1 receptor numbers. ${ }^{34}$ This suggests that the IL-1 induced inhibition of chondrocyte PG synthesis may act together with the defective IGF-1 stimulation of chondrocyte PG synthesis in experimental arthritis.

In the present study we investigated the extent of IL-1 involvement in the IGF-1 nonresponsive state during experimentally induced arthritis in mouse knee joints. We examined the contribution of suppressive mediators produced by the synovium that may abolish the IGF-1 stimulation in in vitro culture systems, investigated a number of specific inflammatory mediators produced in in vitro culture that may interfere with IGF-1 responsiveness, and analysed the role of IL-1 in the induction phase of IGF-1 non-responsiveness. 


\section{Materials and methods}

ANIMALS

Sexually mature female C57 black/6 mice (8-12 weeks old, weights $20-25 \mathrm{~g}$ ) were used. The animals were kept under routine laboratory conditions $\left(21-22^{\circ} \mathrm{C}\right.$, relative humidity $60 \%$ and a 12 hour light-dark cycle), fed a standard commercial pellet diet (RHM, Hope Farms, The Netherlands), and given acidified tap water ad libitum.

INTRA-ARTICULAR IL-1 INJECTIONS

Mouse recombinant IL-1 10 ng (kindly supplied by Dr I G Otterness, Pfizer Central Research, Groten, CT, USA) was injected in a volume of $6 \mu l$ into the joint cavity of the right knee. The left contralateral joint received an equal volume of phosphate buffered saline (PBS). The biological activity of IL-1 was determined using the NOB1 assay. ${ }^{22}$ The IL-1 batch was stored at $-20^{\circ} \mathrm{C}$, and showed constant activity over the period studied. The cartilage was studied at day 1 after intra-articular injection of IL-1.

\section{INDUCTION OF ARTHRITIS}

Arthritis was induced in mouse right knee joints by intra-articular injection of yeast particles (180 $\mu \mathrm{g}$ sterilised Zymosan) (Sigma, St Louis, MO, USA) in pyrogen free saline. This experimental arthritis model is characterised by the development (two to three days after induction of arthritis) of an exudate containing large amounts of polymorphonuclear cells in the joint space, by loss of cartilage PGs, and by inhibition of chondrocyte PG synthesis. Inflammation subsides within a week and because the cartilage damage is reversible, the matrix is subsequently repaired. ${ }^{132735}$ In our subsequent experiments, therefore, cartilage was examined two days after Zymosan induction of arthritis.

IN VIVO ANTI-IL-1 TREATMENT

Anti-IL-1 treatment before the onset of arthritis has been shown to normalise the inhibition of chondrocyte PG synthesis observed during arthritis, but to have no effect on joint swelling and cell influx. ${ }^{22}$ One hour before induction of arthritis, therefore, mice were injected intravenously with a standard dose of $0.6 \mathrm{mg} / \mathrm{ml}$ purified rabbit antimouse IL- $1 \alpha$ and IL-1 $\beta$ antibodies (prepared in our own laboratory by A V de $\mathrm{L} ; 1 \mu \mathrm{g}$ anti-IL- $1 \alpha / \beta$ consistently has a total neutralising capacity of 50-100 pg of both IL-1 subtypes tested in the NOB1-assay ${ }^{22}$ ). As a control, mice were injected intravenously with rabbit IgG.

\section{CARTILAGE CULTURES}

Mice were killed by cervical dislocation and whole patellae were dissected from the right arthritic and left control knee joints, leaving the cartilage fully intact. ${ }^{13}$ The patellae were isolated from the knee joints with minimal amounts of surrounding tissue. The fully intact cartilage ${ }^{1335}$ was used to study radiosulphate incorporation, measured either directly at time zero $(t=0)$, reflecting the in vivo situation, or after culture for 24 or 48 hours. Patellae were cultured in RPMI 1640 medium (Flow Laboratories Irvine, Scotland) supplemented with $2 \mathrm{mmol} / \mathrm{l}$ glutamine, $40 \mu \mathrm{g} / \mathrm{ml}$ gentamycin, and $0 \cdot 1 \%$ ultrapure bovine serum albumin (Sigma) in the presence or absence of recombinant human IGF-1 (Boehringer Mannheim, Germany) in a concentration of $0.25 \mu \mathrm{g} / \mathrm{ml}$, which is close to those in mouse plasma. ${ }^{36}$ The incubations were performed in 24 well cluster dishes at $37^{\circ} \mathrm{C}$ in a humidified atmosphere containing $5 \%$ carbon dioxide.

Suppressive mediators-The relative contribution of suppressive mediators produced by synovial tissue surrounding the patella specimen and by the patella specimen itself during culture was investigated by comparing cultures of patellae containing small amounts of surrounding tissue with those of patellae containing large amounts of surrounding tissue. In addition, cocultures of normal and arthritic patellae were performed in $6.5 \mathrm{~mm}$ transwell systems with a porous cell culture insert (Costar, Cambridge, UK) and the synthetic activity was measured in the cartilage of the normal patellae.

IL-1 and TNF in vitro-To identify which suppressive factors from the arthritic specimen suppressed the IGF-1 response, patellae were cultured in medium containing a mixture of rabbit antimouse antibodies against IL- $1 \alpha$ and IL-1 $\beta$ (prepared in our own laboratory ${ }^{22}$ ), rat antimouse $\mathrm{TNF} \alpha$ (V1q hybridoma cells, kindly given by Dr Krammer, German Cancer Research Center, Heidelberg, FRG). Recombinant human IL-1 receptor antagonist (IL-1 ra) (Synergen, Boulder, Colorado, USA) was included in some cultures, to examine whether its smaller size enabled it to gain access to the chondrocytes and exert a greater influence than the larger antibodies capable of poorer penetration of the articular cartilage. The concentrations of IL-1 ra, anti-IL-1, and anti-TNF used in the present study were based on those previously reported to exert positive effects. ${ }^{11}$ 14-16 19-22 In the mixture of antibodies against IL- $1 \alpha$ and IL- $1 \beta$, both were used at concentrations of $0.06 \mathrm{mg} / \mathrm{ml}$, while $\mathrm{TNF} \alpha$ antibody was used at $30000 \mathrm{U} / \mathrm{ml}$ ( $1 \mathrm{U}$ of the antibody has a neutralising capacity of $90 \mathrm{pg}$ TNF $\alpha$ in the L929 bioassay). IL-1 ra was tested in a concentration range of $0 \cdot 3-100 \mu \mathrm{g} / \mathrm{ml}$. As control for the IL-1 $\alpha$, IL-1 $\beta$, and TNF $\alpha$ antibodies, patellae were cultured with rabbit IgGs and rat IgGs.

Enzymes and reactive oxygen species may induce changes in chondrocyte signalling and thus interfere with IGF-1 responses, so patellae were also cultured in the presence or absence of the enzyme inhibitors leupeptin (Boehringer) or recombinant human tissue inhibitor of metalloproteinases (TIMP) (gift from AMGEN, Thousend Oaks, CA, USA), the oxygen scavenger, catalase, together with horseradish peroxidase (Sigma) or the nitric oxide synthase inhibitor $\mathrm{L}-\mathrm{N}^{\mathrm{G}}$-monomethyl arginine (L-NMMA) (Calbiochem, San Diego, 
California, USA). The inhibitor concentrations we used (leupeptin $0.5 \mu \mathrm{g} / \mathrm{ml}$; TIMP $20 \mu \mathrm{g} / \mathrm{ml}$ ) were analogous to concentrations known to be effective. ${ }^{37-41}$ Catalase and horseradish peroxidase were used together in concentrations of $3 \mathrm{mg} / \mathrm{ml}$ and $12 \mathrm{mg} / \mathrm{ml}$, respectively, and L-NMMA was used at 100 or $1000 \mu \mathrm{mol} / \mathrm{l}$.

IN VITRO INCORPORATION OF RADIOSULPHATE Chondrocyte PG synthesis in patellar cartilage was measured by the incorporation of ${ }^{35} \mathrm{~S}$-sulphate as described previously. ${ }^{35}$ Briefly, cartilage was incubated in RPMI 1640 medium with $1.48 \mathrm{MBq}{ }^{35}$ S-sulphate $\left(\mathrm{Na}_{2}{ }^{35} \mathrm{SO}_{4}\right.$, Du Pont, 's-Hertogenbosch, The Netherlands) for three hours at $37^{\circ} \mathrm{C}$ and then washed three times in physiological saline to remove nonincorporated radiolabel. Patellae were then fixed in $4 \%$ buffered formaldehyde and decalcified in $5 \%$ formic acid for three hours, and the patellar cartilage removed from the surrounding tissue and digested in Lumasolve (Lumac, Landgraaf, The Netherlands) at $60^{\circ} \mathrm{C}$. The quantity of radioactive sulphate incorporated was assayed by liquid scintillation counting. ${ }^{13}$

STATISTICS

Statistical evaluation of the experiments was by one way analysis of variance in combination with Student's $t$ test. A $\mathrm{p}$ value $<0.05$ was considered to be significant.

\section{Results}

IGF-1 NON-RESPONSIVENESS IN ARTHRITIC CARTILAGE

In keeping with previous observations, PG synthesis in patellar cartilage from normal knee joints declined to approximately $50 \%$ in 24 hour culture in the absence of IGF-1, whereas metabolic activity was maintained or even enhanced with physiological concentrations of IGF-1 (fig 1A).27 2930 Cartilage from arthritic knee joints demonstrated suppressed chondrocyte PG synthesis and did not respond to further stimulation with IGF-1 (fig 1B). This non-responsive state of arthritic chondrocytes was maintained with supraphysiological concentrations of IGF-1 (2 $\mu \mathrm{g} / \mathrm{ml}$; data not shown).

SUPPRESSIVE MEDIATORS

When the contribution of suppressive mediators produced during culture by the synovial tissue surrounding the patella was investigated, it was found that IGF-1 responses were significantly lower in both normal and arthritic patellar cartilage embedded in large amounts of tissue (fig 1), indicating that substances in the surrounding tissue from both normal and arthritic cartilage suppressed IGF-1 stimulation of chondrocyte PG synthesis.

Coculture studies of normal and arthritic patellae, in which the synthetic activity was measured only in the normal cartilage showed
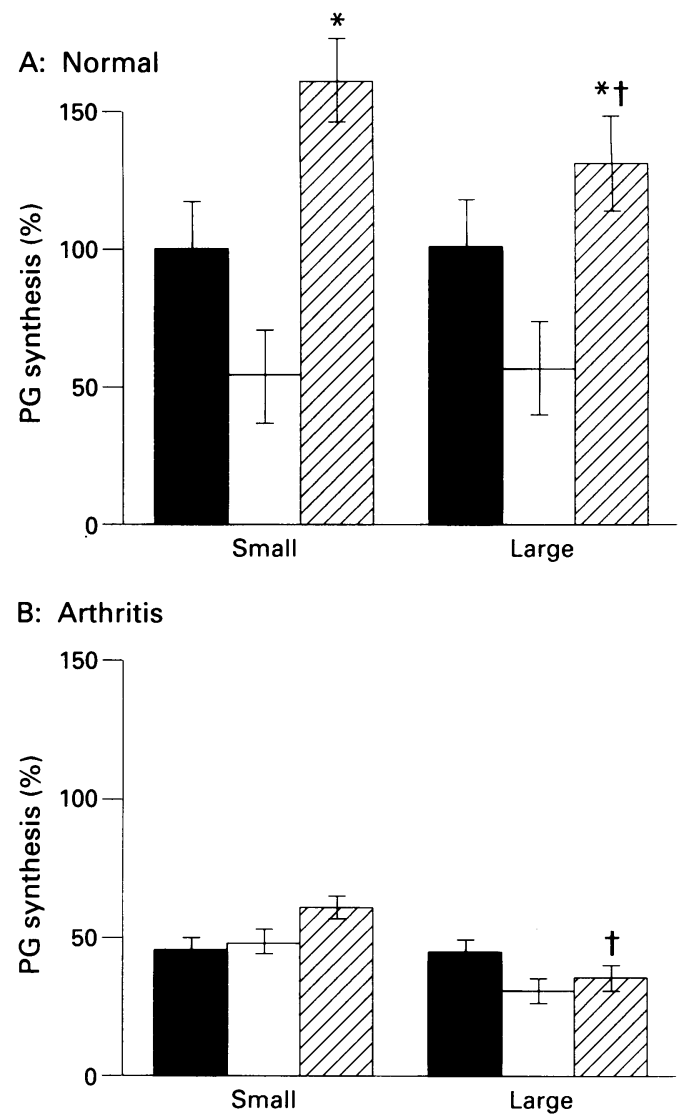

Figure 1 In vitro response to IGF-1 in normal $(A)$ and arthritic $(B)$ mouse patellar cartilage embedded in minimal or large amounts of surrounding tissue: chondrocyte $P G$ or large amounts of surrounding tissue: chondrocyte $P($
synthesis of the cartilage $\left({ }^{35} S\right.$-sulphate incorporation) immediately after isolation of the patellae $(\mathrm{t}=0)(\square)$ or after 24 hours culture with medium alone ( $\square$ ) or medium containing IGF-1 $0 \cdot 25 \mu \mathrm{g} / \mathrm{ml}(\square)$. Data from three experiments (five patellae per group) presented as the mean (SEM) percentage of the control value at $\mathrm{t}=0$. $p<0.05$ compared with radiosulphate incorporation * after culture with medium alone, and tafter culture with IGF-1 in cartilage embedded in small amounts of surrounding tissue.

that IGF-1 stimulation of normal cartilage was reduced in the presence of arthritic specimens, though a complete lack of IGF-1 responsiveness was not achieved (fig $2 \mathrm{~A}$ ).

In the cartilage of normal knee joints that was injected with IL-1 to mimic the in vivo state of arthritic cartilage, PG synthesis was significantly reduced, but IGF-1 was able to enhance the synthetic rate in a subsequent 24 hour culture period. However, when this culture was performed in the presence of arthritic patellae, a pronounced reduction of IGF-1 stimulation was noted. IGF-1 stimulation of IL-1 primed cartilage cultured with arthritic patellae was not significantly different when compared with the ex vivo PG synthetic rate of IL-1 primed cartilage (fig $2 \mathrm{~B}$ ).

ROLE OF IL-1 AND TNF IN VITRO

Figure 3 shows the effect of IL- 1 and TNF modulation of the IGF-1 response. During 24 hours of culture, no significant effect was noted for either cytokine, whereas the synthetic rate was significantly greater when the IL-1 and TNF neutralising culture was extended to 48 hours, in both normal and arthritic specimens; 


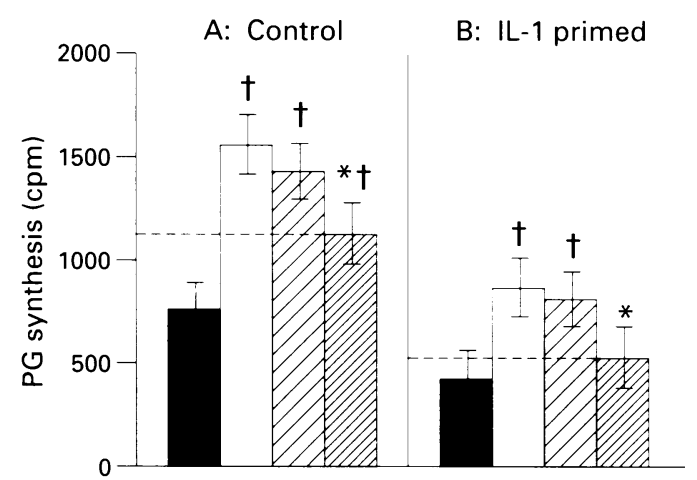

Figure 2 Effect of coculture with mouse arthritic patellae on IGF-1 stimulation of chondrocyte $P G$ synthesis in normal $(A)$ or $I L-1$ exposed (B) mouse patellar cartilage: radiosulphate incorporation determined immediately after isolation of cartilage ( $\mathbf{\square})$, after culture with IGF-1 $0 \cdot 25 \mu \mathrm{g} / \mathrm{ml}$ alone ( $\square$ ), or after coculture for 24 hours with patellae isolated from normal (Z) or arthritic (Z) joints in medium containing $0.25 \mu \mathrm{g} / \mathrm{ml} I G F-1$. Data from three experiments (five patellae per group) presented as the mean (SEM). $p<0.05$ versus radiosulphate incorporation *after coculture with normal patellae, and $+a t \mathrm{t}=0$. Dashed lines (--) inserted to aid comparison of the effects of coculture with arthritic patellae versus $\mathrm{t}=0$ values (significant difference for normal cartilage; no significant difference for IL-1 primed cartilage).

however, the IGF-1 stimulation in arthritic cartilage was marginal and PG synthesis remained clearly reduced compared with that in normal cartilage.
ROLE OF IL-1 IN VIVO

Further to our findings indicating that the use of antibodies against IL-1, TNF, or several inhibitors did not interfere with the IGF-1 response during existing arthritis, we investigated the IGF-1 responses in mice treated with IL- $1 \alpha / \beta$ antibodies at the onset of arthritis, and found that anti-IL-1 treatment almost normalised ex vivo chondrocyte PG synthesis (fig 4). In the absence of IGF-1, PG synthesis declined, but culturing arthritic cartilage from anti-IL-1 treated mice with IGF-1 resulted in a highly significant stimulation of chondrocyte PG synthesis, suggesting their defective IGF-1 signalling had been averted.

\section{INVOLVEMENT OF ENZYMES AND REACTIVE}

OXYGEN SPECIES

The table summarises the effects of several inhibitory factors on the patellar cultures. Leupeptin, an inhibitor of cysteine and serine proteinases, and TIMP, a well known metalloproteinase inhibitor, did not affect IGF-1 responses in a 24 hour culture period. Similarly, a combination of the oxygen radical scavengers, catalase and horseradish peroxidase, did not alter IGF-1 stimulation in normal or arthritic cartilage. The potent nitric oxide synthase inhibitor, L-NMMA, in concentrations of 100 or $1000 \mu \mathrm{mol} / \mathrm{l}$ also failed to
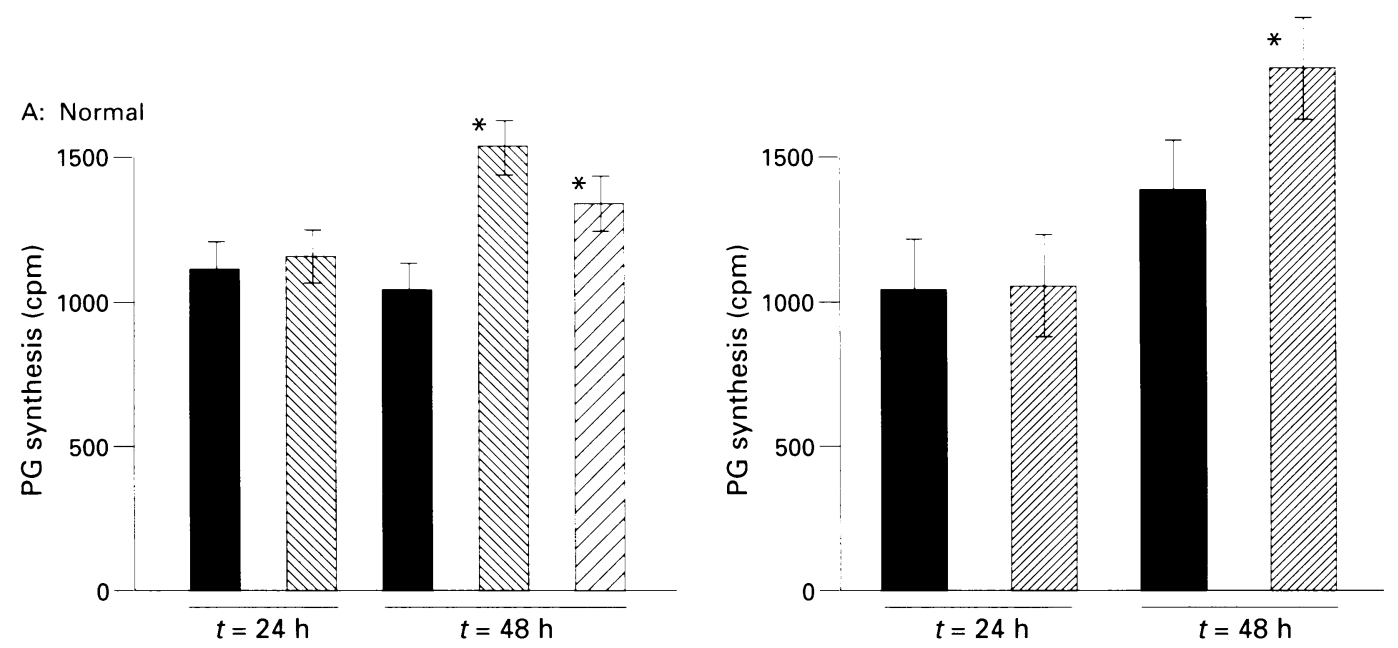

B: Arthritis
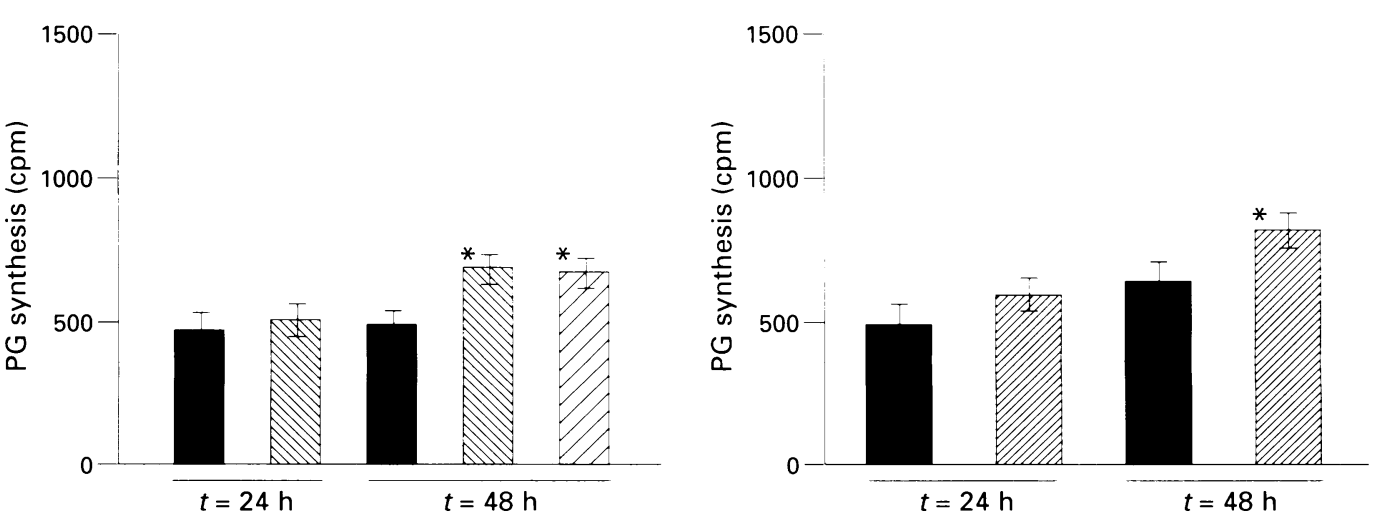

Figure 3 Role of endogenous $I L-1$ or TNF in the IGF-1 response in patellar cartilage from normal $(A)$ or arthritic (B) mouse knee joints: radiosulphate incorporation determined in cartilage after culture for 24 hours or 48 hours without ( or with neutralising antibodies against TNF (30000 U/ml) (Z), IL-1 $\alpha$, and IL-1 $\beta$ (both $0.06 \mathrm{mg} / \mathrm{ml})$ ( $($ ), or with $I L-1 \mathrm{ra} 10 \mu \mathrm{g} / \mathrm{ml}$ ( $\mathrm{\Xi}$ ), in medium containing IGF-1 $0.25 \mu \mathrm{g} / \mathrm{ml}$. IL-1 or TNF data: separate experiments with their individual controls; other data from three experiments (five patellae per group) presented as mean and SEM. ${ }^{*} p<0.05$ compared with radiosulphate incorporation after culture with IGF-1 alone. 


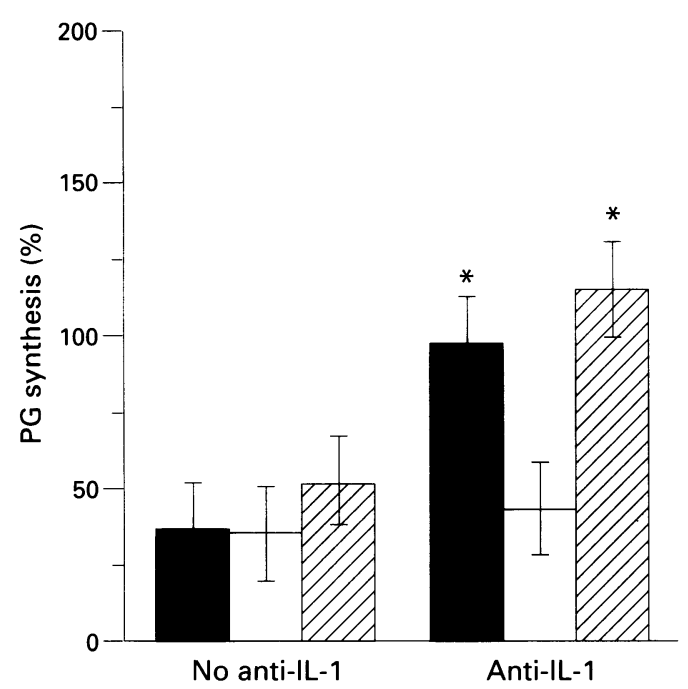

Figure 4 In vitro response to IGF-1 by patellar cartilage from arthritic joints of mice injected with a standard dose of $0.6 \mathrm{mg} / \mathrm{ml} \mathrm{IL-1 \alpha}$ and $I L-1 \beta$ antibodies one hour before the onset of arthritis: chondrocyte PG synthesis ${ }^{35} S$-sulphate incorporation) directly after isolation of the patella $(\mathrm{t}=0)(\mathbf{Q})$ or after 24 hours culture in medium without ( $\square$ ) or with ( $\square$ ) $I G F-10 \cdot 25 \mu \mathrm{g} / \mathrm{ml}$, expressed as a percentage of the control value at $\mathrm{t}=0$ in normal cartilage. Representative results from experiments performed three times (five patellae per experiment). ${ }^{\star} p<0.05$ compared with radiosulphate incorporation after culture with medium alone.

affect either the IGF-1 stimulation in normal cartilage or the poor IGF-1 stimulation in arthritic cartilage.

\section{Discussion}

IGF-1 plays a key role in regulating chondrocyte biosynthetic functions..$^{2-4}$ During experimentally induced arthritis, articular cartilage does not respond to IGF-1 stimulation of chondrocyte PG synthesis, ${ }^{27-30}$ and this IGF-1 non-responsiveness leads to the production of alternative PG monomers, which implies that IGF-1 is essential in the maintenance of cartilage integrity. ${ }^{30}$ Non-responsiveness of arthritic chondrocytes is not restricted to IGF-1, but extends to other growth factors, such as basic fibroblast growth factor, platelet derived growth factor, epidermal growth factor, or transforming growth factor $\beta .^{29}$ This lack of

Effect of a selected range of inhibitors of proteolytic enzymes or reactive oxygen species in vitro on $I G F-1$ stimulation of chondrocyte $P G$ synthesis in cartilage from normal or arthritic mouse knee joints

\begin{tabular}{lll}
\hline & No IGF-1 & $I G F-1$ \\
\hline Normal patellae & & \\
RPMI medium & $258(24)$ & $709(65)$ \\
Leupeptin & $233(38)$ & $820(91)$ \\
TIMP & $258(41)$ & $627(27)$ \\
Catalase/HRPO & $282(34)$ & $640(88)$ \\
L-NMMA 100 $\mu \mathrm{mol} / 1$ & $232(40)$ & $670(70)$ \\
L-NMMA 1000 $\mathrm{mol} / 1$ & $251(51)$ & $859(95)$ \\
Arthritic patellae & & \\
RPMI medium & $168(46)$ & $218(87)$ \\
Leupeptin & $171(14)$ & $187(44)$ \\
TIMP & $215(36)$ & $223(30)$ \\
Catalase/HRPO & $141(34)$ & $203(42)$ \\
L-NMMA 100 $\mu \mathrm{mol} / 1$ & $97(64)$ & $179(32)$ \\
L-NMMA 1000 $\mathrm{mol} / 1$ & $115(21)$ & $164(20)$ \\
\hline
\end{tabular}

Data from three experiments (five patellae per group) presented

TIMP $=$ Tissue inhibitor of metalloproteinases; HRPO = horse-

radish peroxidase; $\mathrm{L}-\mathrm{NMMA}=\mathrm{L}-\mathrm{N}^{\mathrm{G}}$-monomethyl arginine. anabolic signalling during arthritis may contribute to destruction of the cartilage. In the present study we investigated the extent to which IL-1 is involved in the generation or maintenance of the IGF-1 non-responsive state during arthritis.

IL-1 is a potent inhibitor of chondrocyte PG synthesis and is thought to act as key mediator in the pathogenesis of cartilage destruction in arthritic disorders. ${ }^{9} 10$ 16-18 In experimental arthritis models, IL-1 has been shown to be a more potent mediator of cartilage destruction than TNF. ${ }^{22-24} 42$ The present study has shown that unidentified mediators from the surrounding tissue of both normal and arthritic cartilage were able to suppress IGF- 1 responses. Treatment with IL-1 $\mathrm{ra}$, IL- $\alpha / \beta$ antibodies, or TNF antibody did not abolish IGF-1 nonresponsiveness, suggesting that IL-1 or TNF are not the key mediators that maintain IGF-1 non-responsiveness. The enhanced chondrocyte PG synthesis after culture of intact cartilage with anti-IL-1 and anti-TNF is probably specific for anticytokines, and may have reflected release of small amounts of cytokine from the tissue during its isolation. It is likely that the impact of the inflammatory process on the chondrocyte is complex and cannot be expected to be modulated by the elimination of one single factor. Although exposure of the cartilage to IL-1 did not in itself cause IGF-1 non-responsiveness, the exposed cartilage became more susceptible to reduction of the IGF-1 response by other suppressive mediators in the synovium or the chondrocytes, when compared with the ex vivo PG synthetic rate of IL-1 primed cartilage. In addition, anti-IL-1 treatment at the onset of arthritis abolished generation of IGF-1 non-responsiveness. These data imply that IL-1 has an important role in the onset of IGF-1 non-responsiveness but that, once the IGF-1 non-responsiveness is initiated, the importance of IL-1 is lost.

Degrading enzymes and reactive oxygen species have been implicated in the apparent breakdown of articular cartilage during joint inflammation. ${ }^{42-51}$ It is still not understood whether these degradative effects are achieved partly via inhibition of growth factor signalling. In this context, the absence of an IGF-1 response could be the result of IGF-1 receptor stripping, or receptor damage caused by proteolytic enzymes or oxygen metabolites. Recent studies demonstrated positive effects of L-NMMA and TIMP in patellae from arthritic knee joints. These inhibitors may be able to penetrate the cartilage matrix of diseased cartilage comparatively easily, in contrast to poor penetration to the chondrocytes in intact cartilage (A A J Van de Loo, in preparation). In the present study, we found that the metalloproteinase inhibitor, TIMP, and the serine and cysteine proteinase inhibitor, leupeptin, were unable to influence IGF-1 responses in normal and arthritic cartilage. Moreover, the oxygen scavengers catalase and horseradish peroxidase, and the nitric oxide synthase inhibitor L-NMMA did not affect IGF-1 responsiveness. These data suggest that enzymes or oxygen species cannot be indicated 


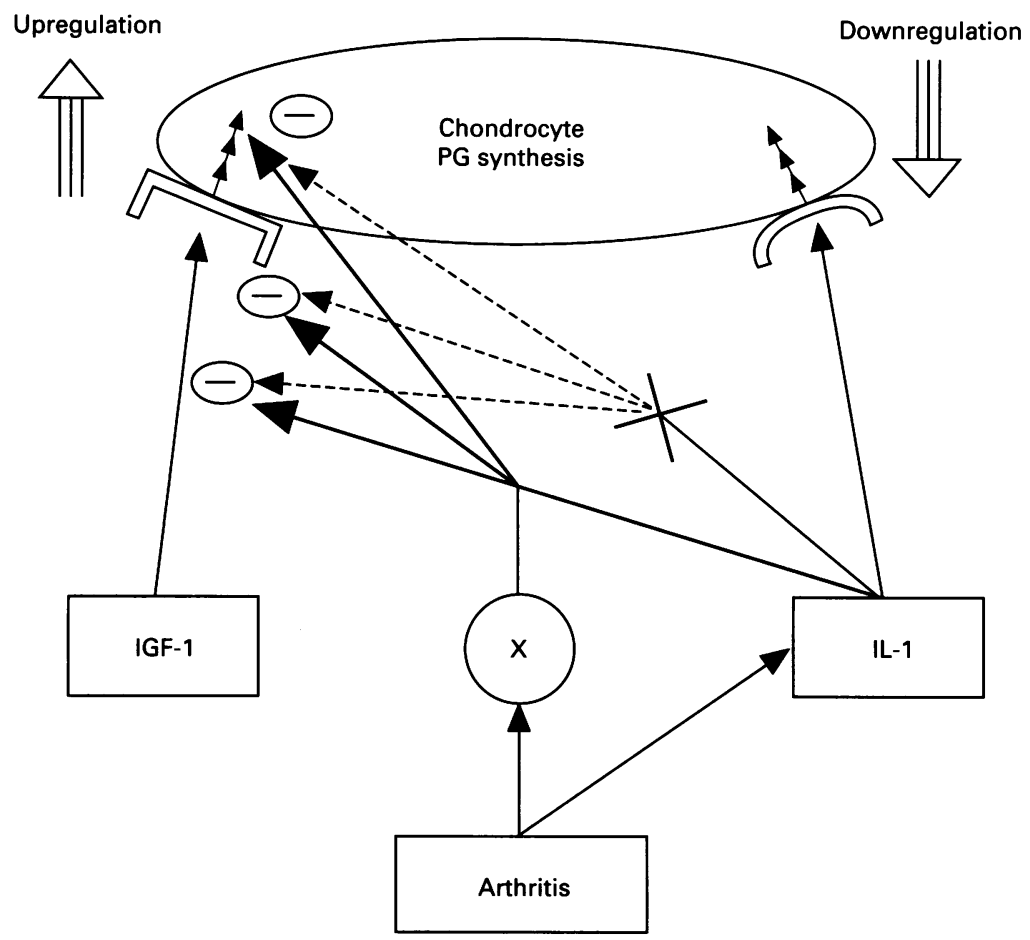

Figure 5 Schematic representation of the interplay of IL-1 and IGF-1 in chondrocyte metabolism. Cartilage chondrocyte proteoglycan synthesis is dependent on the balance of anabolic effects of IGF-1 and catabolic effects of IL-1. During arthritis, chondrocyte $P G$ synthesis is inhibited as a result of excess IL-1, which is sustained by IGF-1 non-responsiveness. IL-1 is not able to induce IGF-1 non-responsiveness, but is indirectly involved (together with the unknown factor, $X$ ) in generation of the phenomenon, as anti-IL-1 treatment can abolish development of IGF-1 non-responsiveness.

as key factors in IGF-1 non-responsiveness,unless, perhaps, their inhibitors had been added to the culture system after irreversible damage had taken place. In keeping with the findings that enzymes or oxygen species do not have a key role in IGF non-responsiveness, we have shown previously that the transient chondrocyte IGF-1 non-responsiveness found after exposure to hydrogen peroxide was not related to IGF-1 receptor damage and that hydrogen peroxide mediated inhibition of chondrocyte PG synthesis was not associated with disturbed IGF-1 signalling. ${ }^{40} 52$ Moreover, we have also shown that IGF-1 receptors on the chondrocyte cell membrane were not decreased in amount during the stage of experimental arthritis in which IGF-1 nonresponsiveness is manifest. ${ }^{53}$ Thus it seems likely that joint inflammation impaired the process of chondrocyte receptor mediated signal transduction, causing a modified biological response. It is of interest that IGF-1 non-responsiveness is not caused by total anergy of the chondrocytes, as forskolin-a stimulator of the adenylate cyclase pathway-is able to enhance chondrocyte PG synthesis in experimentally induced arthritic cartilage. ${ }^{27}$

IGF-1 binding proteins have an affinity for IGF-1 similar to that of the IGF-1 receptor, and increased production of IGF-1 binding protein may therefore diminish IGF-1 bioavailability and affect IGF-1 non-responsiveness during arthritis. ${ }^{55-57}$ Dore et $a l^{57}$ demonstrated that the impaired biological response to IGF-1 by articular chondrocytes from human osteoarthritic cartilage was related to increased production of IGF binding proteins, though it should be noted that ex vivo PG synthesis in osteoarthritic cartilage is at a supranormal level, in contrast with the suppressed chondrocyte PG synthesis in arthritic cartilage. We investigated the non-responsiveness of arthritic chondrocytes in the presence of supraphysiological concentrations of IGF-1, to saturate all available IGF-1 binding proteins and thus exclude a role for excess binding proteins in our findings. The non-responsive state of arthritic chondrocytes was maintained in the presence of these supraphysiological concentrations of IGF-1 $(2 \mu \mathrm{g} / \mathrm{ml})$, implicating inhibition of suppressive mediators produced by the cartilage or synovial tissue, or an intrinsic defect in IGF-1 signalling, rather than IGF-1 binding proteins, in the chondrocyte non-responsiveness. The possibility remains, however, that IGF binding proteins secreted in very high concentrations may be of importance.

In conclusion, lack of IGF-1 responses during arthritis are affected by a complex interaction of suppressive mediators (fig 5). Modulation of one individual mediator in the in vitro culture system does not influence the IGF-1 non-responsive state during arthritis. Priming of the cartilage with IL-1 is not fully responsible for IGF-1 non-responsiveness, but clearly makes the cartilage more susceptible to suppressive mediators. Moreover, anti-IL-1 treatment at the onset of arthritis averts defective IGF-1 signalling. We propose that IL-1 does not induce IGF-1 non-responsiveness, but is involved indirectly in the generation of this phenomenon. The authors wish to thank Monique Helsen for excellent
technical assistance and Dr Robert A Dodds for his critical technical assistance and Dr Robert A Dodds for his critical
review of the manuscript. This study was supported by review of the manuscript. This study was
Toegepast Natuurwetenschappelijk Onderzoek.

1 Hardingham T E, Bayliss M T, Rayan V, Noble D P. Effects of growth factors and cytokines on proteoglycan turnover of growth factors and cytokines on proteoglycan turnover
in articular cartilage. Br $\mathcal{A}$ Rheumatol 1992; 31 (suppl 1): in artic.

2 Hascall V C, Handley C J, McQuillan D J, Hascall G K, Robinson H C, Lowther D A. The effect of serum on biosynthesis of proteoglycans by bovine articular cartilage in culture. Arch Biochem Biophys 1983; 224: 206-23.

3 McQuillan D J, Handley C J, Campbell M A, Bolis S, Millway V E, Herington A C. Stimulation of proteoglycan synthesis by serum and insulin-like growth factor-1 in cultured bovine articular cartilage. Biochem $\mathcal{f}$ 1986; 240: 424-30.

4 Luyten F P, Hacall V C, Nissley S P, Morales T I, Reddi A H. Insulin-like growth factors maintain steadystate metabolism of proteoglycans in bovine articular cartilage explants. Arch Biochem Biophys 1988; 267: 416-25.

5 Osborn K D, Trippel S B, Mankin H J. Growth factor stimulation of adult articular cartilage. F Orthop Res 1989; 7: 35-42.

6 Tyler J A. Insulin-like growth factor 1 can decrease degradation and promote synthesis of proteoglycan in cartilage exposed to cytokines. Biochem f 1989;260 543-8.

7 Schalkwijk J, Joosten L A B, Van den Berg W B, Wijk J J, Van de Putte L B A. Insulin-like growth factor stimulation of chondrocyte proteoglycan synthesis by human synovial fluid. Arthritis Rheum 1989; 32: 66-71.

8 Benton H P, Tyler J A. Inhibition of cartilage proteoglycan synthesis by interleukin-1. Biochem Biophys Res Commun 1988; 145: 421-8.

9 Pettipher E R, Higgs G A, Henderson B. Interleukin-1 induces leukocyte infiltration and cartilage proteoglycan degradation in the synovial joint. Proc Natl Acad Sci USA 1986; 83: 8749-53.

10 Page-Thomas D P, King B, Stephens T, Dingle J T. In vivo studies of cartilage regeneration after damage induced by

11 Smith R J, Chin J, Sam L M, Justen J M. Biological effects of an interleukin-1 receptor antagonist protein on of an interleukin-1 receptor antagonist protein on cyte responsiveness. Arthritis Rheum 1991; 34: 78-83. 
12 Chandrasekhar S, Harvey A K, Hrubey P S. Intraarticula administration of interleukin-1 causes prolonged suppression of cartilage proteoglycan synthesis in rats. Matrix 1992; 11: 1-10.

13 Van den Berg W B, Kruijsen M W M, Van de Putte L B A Zwarts W A. Antigen-induced arthritis and zymosaninduced arthritis in mice: Studies on in vivo cartilage Pathol 1981; 62: 308-16.

14 Wooley P H, Whalen J D, Chapman D L, et al. The effect of an interleukin-1 receptor antagonist protein on type II collagen-induced arthritis in mice. Arthritis Rheum 1993; 36: 1304-14.

15 Lethwaite J C, Blake S M, Hardingham T E, Warden P J, Henderson $B$. The effect of recombinant human interleukin-1 receptor antagonist on the induction phase of antigen-induced arthritis in the rabbit. $\mathrm{Br} \mathcal{F}$ Rheumatol 1994; 21: 467-72.

16 Henderson $B$, Thompson $R \quad C$, Hardingham $T$, Lewthwaite $J$. Inhibition of interleukin-1-induced synovitis and articular cartilage proteoglycan loss in rabbit knee by recombinant human interleukin-1 receptor antagonist. Cytokine 1991; 3: 246-9.

17 Arend $W$ P, Dayer J M. Inhibition of the production of interleukin-1 and tumor necrosis factor $\alpha$ in rheumatoid arthritis. Arthritis Rheum 1995; 38: 151-60.

18 Verschure $P$ J, Van Noorden C J F. The effects of interleukin-1 on articular cartilage destruction as observed in arthritic diseases and its therapeutic control. Clin Exp Rheum 1990; 8: 303-13.

19 Williams R O, Feldman M, Maini R N. Anti-tumor necrosis factor ameliorates joint disease in murine collagen-
induced arthritis. Proc Natl Acad Sci 1992; 89: 9784-8.

20 Thorbecke G J, Shah R, Leu C H, Kuruvilla A P, Hardison A M, Palladino $M$ A. Involvement of endogenous tumor necrosis factor $\alpha$ and transforming growth factor $\beta$ during induction of collagen type II
arthritis in mice. Proc Natl Acad Sci USA 1992; 89:

21 Elliot M J, Maini R N, Feldman M, et al. Treatment of rheumatoid arthritis with chimeric monoclonal antibodies to tumor necrosis factor $\alpha$. Arthritis Rheum 1993; 12: 1681-90.

22 Van de Loo A A J, Arntz O J, Otterness I G, Van den Berg W B. Protection against cartilage proteoglycan synthesis inhibition by anti-interleukin 1 antibodies in experimental arthritis. $\mathcal{F}$ Rheumatol 1992; 19: 348-56.

23 Van de Loo A A J, Joosten L A B, Van Lent P L E M Arntz O J, Van den Berg W B. Role of interleukin-1, tumor necrosis factor $\alpha$ and interleukin- 6 in cartilage proteoglycan metabolism and destruction: effect of in situ blocking in murine antigen- and zymosan-induced arthritis. Arthritis Rheum 1995; 38: 164-72.

24 Van de Loo A A J, Arntz O J, Bakker A C, Van Lent P L E M, Jacobs M J M, Van den Berg W B. Role of interleukin-1 in antigen induced exacerbations of murine arthritis. Am f Pathol 1995; 146: 239-49.

25 Van den Berg W B, Van de Loo A A J, Otterness I, Arntz O J, Joosten L A B. In vivo evidence for a key role of IL-1 in cartilage destruction in experimental arthritis. In: Parnham M J, Bray M A, Van den Berg W B, eds. Drugs in inflammation. Agents Actions 1991; 32 (suppl): 159-63.

26 Van den Berg W B, Joosten L A B, Helsen M M A, Van de Loo A A J. Amelioration of established murine collagen-induced arthritis with anti-IL-1 treatment. Clin Collagen-induced arthritis with ant

27 Schalkwijk J, Joosten L A B, Van den Berg W B, Van de Putte L B A. Chondrocyte nonresponsiveness to insulinlike growth factor 1 in experimental arthritis. Arthritis Rheum 1989; 32: 894-900.

28 Van den Berg W B, Joosten L A B, Schalkwijk J, Van de Loo F A J, Van Beuningen H M. Mechanism of cartilage destruction in experimental arthritis: lack of IGF-1 responsiveness. In: Lewis A J, Doherty $N$, Ackerman N R, eds. Therapeutic approaches to inflammatory

29 Verschure P J, Joosten L A B, Van der Kraan P M, Van den Berg W B. Responsiveness of articular cartilage from normal and inflamed mouse knee joints to various growth factors. Ann Rheum Dis 1994; 53: 455-60.

30 Verschure P J; Van der Kraan P M, Vitters E L, Van den Berg $W$ B. Stimulation of proteoglycan synthesis by triamcinolone acetonide and insulin-like growth facto in normal and arthritic murine articular cartilage. f Rheumatol 1994; 21 : 920-5.

31 Rayan V, Hardingham $T$. The recovery of articular cartilage in explant culture from interleukin-1 $\alpha$ : effects on proteoglycan synthesis and degradation. Matrix Biol 1994; 14: 263-71.

32 Lazarus D D, Moldawer L L, Lowry S F. Insulin-like growth factor 1 activity is inhibited by interleukin-1a, tumor necrosis factor $\alpha$ and interleukin-6. Lymphokin Cytokine Res 1993; 12: 219-23.

33 Lin T, Wang D, Nagpal M L, Chang W, Calkins J H. Downregulation of Leydig cell insulin-like growth factor-1 gene expression by interleukin-1. Endocrinology 1992; 130: expression
34 Matsumoto T, Tsukazaki T, Enomot $H$, Iwasaki $K$, Yamashita $S$. Effects of interleukin-1 $\beta$ on insulin-like growth factor-1 autocrine/paracrine axis in cultured rat articular chondrocytes. Ann Rheum Dis 1994; 53 128-33.

35 Van den Berg W B, Kruijsen M W M, Van de Putte L B A The mouse patella assay: an easy method of quantitating articular cartilage chondrocyte function in vivo and in vitro. Rheumatol Int 1982; 1: 165-9.

36 Van Beuningen H M, Arntz O J, Van den Berg W B. In vivo effects of interleukin-1 on articular cartilage: Prolongation of proteoglycan metabolic disturbance in old mice. Arthritis Rheum 1991; 34: 606-15.

37 Ellis A J, Curry V A, Powell E K, Cawston T E. The prevention of collagen breakdown in bovine nasal cartilage by TIMP and TIMP-2 and a low molecular weight synthetic in

38 Shingu M, Isayama T, Yasutake C, et al. Role of oxygen radicals and IL-6 in IL-1 dependent cartilage matrix degradation. Inflammation 1994; 18: 613-23.

39 Everts V, Hembry R M, Reynolds J J, Beertsen W. Metalloproteinases are not involved in the phagocytosis of collagen fibrils by fibroblasts. Matrix 1989; 9: 266-76.

40 Schalkwijk J, Van den Berg W B, Van de Putte L B A, Joosten L A B, Van de Bersselaar L. Cationization of catalase, peroxidase and superoxide dismutase: effect of improved intraarticular retention on experimental arthritis in mice. 7 Clin Invest 1985; 76: 198-205.

41 Jarvinen T A H, Moilanen T, Jarvinen T L N, Moilanen E Nitric oxide mediates interleukin-1 induced inhibition of glycosaminoglycan synthesis in rat articular cartilage. Mediators of Inflammation 1995; 4: 107-11.

42 Joosten L A B, Helsen M M A, Van den Berg W B. Accelerated onset of collagen-induced arthritis by remote inflammation. Clin Exp Immunol 1994; 97: 204-11.

43 Krane S M, Conca W, Stephenson M L, Amento E P Goldring M B. Mechanisms of matrix degradation in rheumatoid arthritis. Ann NY Acad Sci 1990; 580 340-54.

44 Murphy G, Reynolds J J. Extracellular matrix degradation. In: Royce P M, Steinmann B, eds. Connective tissue and its heritable disorders. New York: Willey-Liss Inc, 1993; 287-316.

45 Martel-Pelletier J, McCollum R, Fujimoto N, Obata $\mathrm{K}$ Cloutier J M, Pelletier J P. Excess of metalloproteinase over tissue inhibitor of metalloproteinase may contribute over tissue inhibitor of metalloproteinase may contribute to cartilage degradation in osteoarthritis

46 Dewar C L, Harth M. Superoxide production from cytokine-treated adherent rheumatoid neutrophils. Clin Invest Med 1994; 17: 52-60.

47 Charles I G, Palmer R M J, Hickery M J, et al. Cloning, characterization and expression of a cDNA encoding an inducible nitric oxide synthase from the human
chondrocyte. Proc Natl Acad Sci USA 1993; 90: 11419-23.

48 Stadler J, Stefanovic-Racic M, Billiar T R, et al. Articular chondrocytes synthesize nitric oxide in response to cytokines and lipopolysaccharide. $\mathcal{F}$ Immunol 1991; 147; 3915-20.

49 Palmer R M J, Hickery M S, Charles I G, Moncada S Bayliss $M$ T. Induction of nitric oxide synthase in human Bayliss M T. Induction of nitric oxide synthase in human 398-405.

50 Taskiran D, Stefanovic-Racic M, Georgescu H, Evans C. Nitric oxide mediates suppression of cartilage proteoglycan synthesis by interleukin-1. Biochem Biophys Res Comm 1994; 200: 142-8.

51 Hauselman H J, Oppliger L, Michel B A, StefanovicRacic M, Evans $\mathrm{C} H$. Nitric oxide and proteoglycan biosynthesis by human articular chondrocytes in alginate culture. FEBS Lett 1994; 352: 361-4.

52 Joosten L A B, Helsen M M A, Van den Berg W B. Transient chondrocyte non-responsiveness to insulinlike growth factor-1 upon $\mathrm{H}_{2} \mathrm{O}_{2}$ exposure is not related to IGF-1 receptor damage. $\mathcal{f}$ Rheumatol 1991; 18: 585-90.

53 Verschure P J, Van Marle J, Joosten L A B, Van den Berg W B. Localization and quantification of the insulinlike growth factor-1 receptor in mouse articular cartilage by confocal laser scanning microscopy. $₹$ Histochem by confocal laser scanning $1994 ; 42:$ 765-73.

54 Verschure P J, Van Marle J, Joosten L A B, Van den Berg W B. Chondrocyte IGF-1 receptor expression and responsiveness to IGF-1 stimulation in mouse articula cartilage during various phases of experimentally induced arthritis. Ann Rheum Dis 1995; 54: 645-53.

55 Tesch H G, Handley C J, Cornell H J, Herrington A C. Effects of free and bound insulin-like growth factors on proteoglycan metabolism in articular cartilage explants. f Orthop Res Soc 1992; 10: 14-22.

56 Baxter R C. Circulating binding proteins for the insulin-like growth factors. Trends Endocrinol Metab 1993; 4: 91-6.

57 Dore S, Pelletier J-P, DiBattista J A, Tardif G, Brazeau P, Martel-Pelletier J. Human osteoarthritic chondrocytes possess an increased number of insulin-like growth factor 1 binding sites but are unresponsive to its stimulation. Arthritis Rheum 1994; 37: 253-63. 